\title{
Román Álvarez Rodríguez, Australia y Nueva Zelanda, Un mundo al otro lado del mundo, Devonport, Auckland, 2019, 204 pp.
}

Espíritu inquieto donde los haya, y hombre curioso como el que más, Román Álvarez Rodríguez, catedrático de filología inglesa de la Universidad de Salamanca, no limita sus publicaciones a las relativas al estricto estudio académico y científico, sino que escribe también libros que son periféricos a los más atingentes a su especialidad. Un ejemplo podría ser este volumen de 2019 titulado Australia y Nueva Zelanda. Un mundo al otro lado del mundo. Ambas presentan nexos comunes, y en ambas el viaje resulta asunto primordial, solo que en la primera quienes viajan son los irlandeses y lo hacen a España, recalando en Salamanca un núcleo muy importante y fecundo de ellos, mientras en la segunda quien viaja es el propio autor, y no entre países del mismo continente, y para quedarse en destino, sino para establecer lazos diversos entre la Universidad salmantina y la neozelandesa de Auckland, y en paralelo lazos asimismo con colegas de aquella zona del planeta que, con el paso del tiempo y, como no podía ser de otro modo en el caso de Román Álvarez Rodríguez, se convertirán en estrecha amistad.

En el subtítulo de su libro, el autor nos ha proporcionado un paratexto que añade notas clave en su idiosincrasia personal, las de la naturalidad y sencillez, perceptibles al referirse a esas páginas como 'cuaderno', un cuaderno escrito por un 'viajero'. Una cita de Saramago, después de otra cervantina, preceden al prólogo. La del nobel portugués dice así: "El viaje no termina nunca: solo los viajeros terminan." Buen anticipo para un preliminar que lleva por título "Introducción: Viaje a Down Under.". Veamos unas cuantas cosas de las que ahí se dicen.

Apenas empezamos el recorrido lector nos sale al paso una citación de Malte L. Brigge, extraída de sus Cuadernos. Es esta: "para escribir un solo verso es necesario haber visto muchas ciudades, hombres y cosas." En el fondo de esta hipérbole late un tipo de pedagogía que muchos escritores suscribirían. Guillermo Díaz-Plaja dijo que cada viaje depara la oportunidad de escribir poesía, aunque no son únicamente versos los que propicia, sino escrituras diferenciadas, como lo acredita el libro objeto de esta reseña.

Sigamos leyendo porque Román Álvarez Rodríguez enseguida efectúa el contrapunto de que "la historia de todas las literaturas nos ofrece ejemplos de buenos escritores que apenas pusieron un pie fuera de casa a lo largo de su carrera." Y es verdad, aunque en cada caso habría de calibrarse a cuánto asciende el adverbio 'apenas'. Claro que se nos recuerda que el viaje con la imaginación, tan propia de los escritores, e incluso al alcance de los que no se dedican a escribir, permite que viajemos a cualquier latitud. De un poeta amigo mío es una composición maravillosa sobre Buenos Aires sin haber pisado nunca ese suelo. Y los ejemplos podrían ser muchísimos. Y es que, como 
señala el autor del libro, el hecho mismo de escribir ya constituye un viaje imaginario por el que nos adentramos "en el propio interior y en lo extraño."

Mark Twain escribió un libro de viajes titulado Siguiendo el Ecuador. Viaje alrededor del mundo, resultado de un periplo que le llevaría, entre otros lugares del globo, a Australia. Nos lo recuerda Álvarez Rodríguez bien oportunamente, porque también él ha ido, aunque no sea recorriéndose el mundo en una sola singladura, a Australia y a Nueva Zelanda. Lo ha hecho al amparo de la Fundación Buena Vista, y con objeto de potenciar las relaciones de la Universidad de Salamanca donde enseña e investiga con la ya citada de Auckland.

El primero de los capítulos se dedica al país y continente australiano. Y explica el autor que sus aborígenes lo habitaron desde hace unos sesenta mil años, considerándolo una de las culturas más antiguas del mundo. Atendiendo a este dato, entonces esa zona del planeta no sería acaso "una de las", como cautelarmente dice, sino la más antigua del orbe con diferencia, aventajando en antigüedad a las civilizaciones china y mesopotámica.

Aunque algunos europeos ya habían llegado a esos lugares antes de que lo hiciese el capitán James Cook, fue este quien trazaría el mapa de tan vasto territorio hacia 1770, reclamándolo para la corona británica, sigue explicando el autor, quien recuerda asimismo que Barron Field, en uno de sus poemas, consideró a dicho navegante "nuestro Colón del Sur".

Iban a ser los ingleses los que colonizaron esos horizontes, haciéndolo de modo y manera que los nativos "fueron despojados de sus tierras y a muchos se les deportó a la isla de Flinders...". No se andaban con demasiados miramientos, por tanto, esos colonizadores procedentes de Gran Bretaña, que ya desde los inicios de su colonización harían de unos parajes tan lejanísimos para ellos un penal para recluir a los criminales, lo que ciertamente era un argumento bien preventivo del delito saber que a uno podían llevarle allí por sus crímenes. La denuncia del maltrato cruento de los aborígenes por los colonizadores fue el asunto de un poema muy emblemático de las letras australianas. Lo compuso una de sus primeras escritoras, Eliza Hamilton Dunlop. Aludimos a "La madre aborigen", publicado en 1838. En sus versos se postulaba que de los aborígenes podían aprender mucho los blancos, como por ejemplo no solo el alto concepto de los lazos familiares, sino el "sentimiento de pertenencia a un grupo que define y organiza la vida colectiva y el bienestar de todos sus miembros".

A fines del XIX, señala Álvarez Rodríguez, Darwin ya anotó que la población australiana estaba obsesionada por acumular riquezas, un dato en convergencia con el que atestiguaba en 1922 D. H. Laurence, según el cual todo se medía por su precio de coste en ese país del que Álvarez Rodríguez pondera su rico subsuelo mineral, su varia fauna y flora, su capacidad de poder sobrevivir en base a sus propios recursos en caso de situaciones catastróficas.

Pese al turbio pasado al que ya nos hemos referido, Australia fue superando ese punto de partida, porque actualmente, como escribe el autor del libro, hoy es "una de las naciones más multiculturales del mundo", lo que no obsta para informar también 
a los lectores de que la adquisición de derechos por los aborígenes ha sido lenta, y son aún mirados a veces con recelos discriminatorios. Tampoco se retrae en señalar que algunas asociaciones defensoras de los derechos humanos han denunciado distintos aspectos de la política gubernamental seguida en materia migratoria, que afecta sobre todo a gentes asiáticas.

De varias cuestiones onomasiológicas se ocupa luego Álvarez Rodríguez antes de finalizar este capítulo. La que aborda primero es la del nombre del continente. Según los australianos, aunque no solo ellos, que se llame así se debe al navegante y cartógrafo inglés Matthew Flinders. Más tinta emplea en recordar la atribución del nombre al portugués, de apellido asturiano, Pedro Fernández de Quirós. En uno de los viajes de este navegante hacia las llamadas Nuevas Hébridas, en concreto el que hizo desde Perú en 1606, tomó posesión de esta zona, denominándola 'Austrialia' (con dos íes, y por los Austrias), "desde esta parte del Sur hasta el Polo". Su caso se asemeja hasta cierto punto con el de Colón, porque tampoco llegó al sitio esperado, sino a otro imprevisto.

También se refiere Álvarez Rodríguez a la denominación de Pacífico dada por el portugués Fernando de Magallanes, al servicio de Carlos I, al Océano de ese nombre. Se lo dio por haber encontrado calmadas sus aguas. Aprovecho la ocasión para decir que Unamuno se refería a este nombre diciendo que el tiempo había acabado demostrando que, de pacífico, tiene muy poco, y los papeles y pantallas noticiosas lo evidencian de vez en vez. Y finalmente se nos informa de la curiosidad de que tanto Australia como Nueva Zelanda cuentan con nombres topográficos españoles, entre ellos los de Corunna, Vitoria, Valencia y Salamanca, que es como se conoce a la Plaza Mayor de Hobart, capital del insular estado australiano de Tasmania, además de utilizarse en otros lugares, como se verá más adelante.

El capítulo sobre el continente australiano es, con diferencia, el más extenso del libro, de ahí que los sucesivos sean más o menos breves, empezando por el titulado "Melburne: una ciudad con personalidad", donde nos enteramos de que esa urbe, gracias a sus parques y jardines, es considerada la ciudad verde australiana, y además alberga una cuantiosa parte de las 170 nacionalidades que moran en el país. No sin humor, Álvarez Rodríguez explica en este capítulo un pequeño anecdotario de las peripecias vividas en el hotel en el que se alojó, el "Carlton Terrace", con un peculiar funcionamiento, acaso en las antípodas, y nunca mejor dicho, de tantos hoteles de ese nombre como hay por el mundo, algunos en España.

En los dos capítulos siguientes, el catedrático salmantino da cuenta de distintos encuentros y menesteres académicos llevados a cabo en la Universidad de Melburne, y cuyo detalle ahorraremos al lector. No así las dos salpicaduras curiosas que abren y cierran el capítulo "Cita con David Yenken". En ambos supuestos se da vía libre a la ironía, tan propia de Álvarez Rodríguez, primero al dejar en evidencia clamorosa a algunos estudiantes propugnando un comunismo exacerbado, y segundo al recordarnos cómo el Plan Marshall nos beneficiaba con leche en polvo teniendo en España como teníamos tanta vaca lechera que ordeñar. 
Los tres capítulos que siguen los protagonizan Sydney, el pueblo de Cowra y Camberra. En la primera de estas tres localidades, que el autor califica como puerta de Australia, se resaltan los abundantes sitios merecedores de ser visitados, subrayándose entre ellos la ópera, de la que se nos recuerda que fue declarada Patrimonio de la Humanidad en 2007. El viajero se demora más adelante en el Paseo de los escritores, no sin advertirnos de que no es el único que hay en el mundo dedicado a los artífices de la pluma. El de Sydney se concentra, homenajeándoles con una lápida, en aquellos que han hablado o escrito sobre la ciudad, por ejemplo Twain, Conrad, y un largo etcétera. Tan casual como sorprendente y agradable fue el encuentro en esa urbe con una exalumna de los cursos de verano salmantinos, reproduciéndose una foto de Salamanca procedente de un álbum de esa australiana que escribe poemas y de la que se atestigua que "lleva a Salamanca y su universidad adherida a lo más profundo de su corazón".

Los japoneses acaparan casi por completo cuanto se dice acerca del pueblo de Cowra, enclavado entre Orange y Camberra. En esas páginas se cuentan sucesos relativos al campo de concentración que allí se mantuvo durante la Segunda Guerra Mundial, y en el que se produciría una gran fuga de cautivos nipones, lo que rememora un pequeño museo conmemorativo de la evasión. Hay en esta población un cementerio de los japoneses y un jardín japonés que abarca nada más y nada menos que cinco hectáreas, lo que resulta muy excepcional.

Álvarez Rodríguez explica luego en qué consistió su visita a la Embajada de España en Camberra, en la que, además de ponerles al corriente sobre la Fundación Vista Linda, les participó la conmemoración del VIII Centenario de la fundación de la Universidad de Salamanca, que no es solo el de dicha institución tan centenaria, "sino de la Universidad española en su conjunto.", recalca.

A quienes sepan del gran interés de Álvarez Rodríguez por el mundo que él mismo, con resabio clasicista, denomina 'pastoril', no se sorprenderán si dedica cuatro capítulos a la ruralía australiana, el primero a sus ovejas merinas, a las que siempre tiene muy presentes. Recordaré que todos los domingos, y desde ya más de media docena de años, publica en La Gaceta Regional de Salamanca una columna de opinión que lleva el título de "Churras y merinas", un lema en el que se mencionan dos tipos de ovejas que no se han de mezclar, como aconseja un dicho bien conocido. Sin embargo, el autor mezcla una cosa con otra, a esta con la de más allá, y con gracejo, en sus colaboraciones periodísticas semanales. Y justamente una amplia selección de estos artículos los ha agrupado en 2019 en un libro al que dio el título de Churras y merinas, subtitulándolo Visiones, impresiones, realidades.

"Las ovejas merinas de Australia" es el capítulo con el que se inicia esta serie cuatripartita, y donde se detalla el origen castellano de este ganado lanar que llegó a tan lejanas tierras, desde las zonas originarias, a finales del siglo XVIII. Ahí se pondera que, a diferencia de lo ocurrido en España, el potencial de estos animales no se ha descuidado, sino que en Australia supieron valorarlo y han logrado alcanzar de él una alta cota de productividad. Y se nos recuerda al término de este capítulo que en 
2016 visitaron algunos ganaderos australianos la zona de origen de esta raza, Barrios de Luna, y más en concreto Abelgas, cuna de la transhumancia, siendo nombrados pastores honoríficos del lugar. Fue en el mismo año en el que Román Álvarez Rodríguez recibió el título de Pastor Mayor de los Montes de Luna.

Pocos desconocen la existencia de la ruta asiática de la seda que partía de China, pero es interesante conocer asimismo la antigua ruta lanar australiana, la Old Wool Road, iniciada en 1841. A esta cuestión se dedica el segundo capítulo de la gavilla, centrándose el tercero en una explotación ganadera, y el cuarto a "Las cabras de Angora de Wee Jasper", referente a una clase de cabras muy distinto a las de España, y consignándose también que en una zona de Salamanca se ha comenzado a poner en marcha, de modo todavía experimental, esta peculiarísima variante caprina.

En las páginas tituladas "Los Archivos Nacionales de Australia y otras curiosidades", se anotan varias observaciones sobre el país que resultan bien llamativas, como por ejemplo la de que la fiebre censora desplegada durante décadas (de los veinte a los sesenta del pasado siglo), y la prohibición de la venta de alcohol en Semana Santa atestiguan un puritanismo que no se compadece con el grado de profesionalidad con la que se publicitan anuncios de contacto. La violencia de género no es menor que en otras partes del mundo, pero sí constituye otro rasgo peculiar el alto número de suicidios, lo que permite al autor el diplomático comentario de que "Algo debe de pasar en una sociedad en la que el suicidio cobra cada día cifras más elevadas."

Van a ir sucediéndose luego distintos capítulos sobre Nueva Zelanda, donde se encuentra Auckland, así como la Fundación Vista Linda. Al igual que hizo respecto a Australia, el autor efectúa una presentación de este país, a 24 horas de vuelo desde España. Comienza recordándonos que desde el siglo XIII se asentaron en el territorio tribus maoríes, y señala que el capitán Cook, en nombre del rey de Inglaterra, tomó posesión de las islas -las principales son dos- en 1769. No obstante, no sería hasta 1840, es decir casi setenta años después, que se oficializó la vinculación política con la corona británica, representada por un gobernador general. En 2011 este cargo lo ocuparía por vez primera un maorí, y como resultado de reivindicaciones que, sobre todo desde 1975, se fueron produciendo para la preservación de la cultura autóctona y para el logro de los mismos privilegios que tenían los anglosajones.

De manera sucinta añadiré otras informaciones que en el libro se aportan: la lengua oficial es el inglés, hablado en todo el país, pero también el maorí, en cuya cosmología se ha considerado al árbol Tane Mahuta protector de la vida y padre de las criaturas todas, lo que supone una singularidad incomparable. El ave kiwi, cuyo nombre coincide con el que tiene el fruto originario de China, está casi desapareciendo, lamentablemente, pese a ser el icono simbólico más representativo de Nueva Zelanda. Por lo que hace a la oveja merina, se subraya la extraordinaria cotización internacional de la lana neozelandesa, obtenida con ganado de origen español.

Digno de nota es el orgullo que sienten los neozelandeses al compararse con los británicos, porque creen que les aventajan en todo, y acaso tengan muchas razones de peso para creerlo. De lo que no hay duda es de que este país fue el primero del mundo 
en autorizar el voto femenino sin restricción alguna, porque con anterioridad se había ejercido este derecho en otros países, pero con cortapisas de tipo distinto. También resulta merecedor de elogio que apenas se despueble el campo a costa de la migración a las ciudades, lo que acredita la riqueza del agro neozelandés. Otro rasgo del perfil de Nueva Zelanda lo constituye su multiculturalidad, siendo de procedencia asiática, mayormente india y china, una cuarta parte de su población.

Auckland es el eje en torno al que pivotan los tres capítulos que van a sucederse acto seguido. En el primero se aborda su paisaje urbano, en el segundo las propuestas de colaboración posibles entre la Universidad de Salamanca y la de Auckland, donde estudian unos 40. 000 alumnos; y en el tercero otros aspectos, algunos problemáticos, relativos a la enseñanza universitaria tanto en Nueva Zelanda como en España.

Álvarez Rodríguez estima en mucho la alta preocupación por la naturaleza que ha acreditado Nueva Zelanda, tan perceptible en el proteccionismo que reciben sus parajes naturales, y sobre todo su árbol más emblemático, el kauri. De Auckland anota también que se asienta sobre antiguos conos volcánicos que suman varias decenas, la mayoría convertidos en espacios recreativos.

El capítulo "El Bullshit Corner de Puhoi" encabeza una serie de ellos que se enmarcan fuera de Auckland. La visita a Puhoi le sirve al autor para proporcionar algunos datos interesantes acerca de la estadía de Manuel Vázquez Montalbán en esa localidad, y como consecuencia de su viaje a Nueva Zelanda becado con la misma beca que él, otorgada por la Fundación Vista Linda. La obra póstuma del tan reconocido novelista español, Milenio Carvallo II. En las antípodas (2004), ocurre en escenario neozelandés. Y fue precisamente regresando de Nueva Zelanda, y en escala en Bangkok, cuando falleció el 18 de octubre de 2003.

Dejando atrás Puhoi, el viajero va a relatarnos diversos recorridos por Nueva Zelanda antes de referirse a su capital, Wellington. Primero se dirige al Norte y realiza varias paradas, contándonos algunas de las singularidades de cada lugar visitado. Obviaré las relativas a Kawakawa, pero no las de Rusell, a donde ya había recalado el navío Endevour del capitán James Cook. A este lugar, llamado por los maoríes Kororareko, los misioneros lo tildaron de "la Gomorra del Pacífico". Allí se encuentra la tumba de la primera mujer blanca neozelandesa, y asimismo la residencia Duque of Marlborough Hotel, en la que se alojó el escritor californiano Zane Grey, al que se deben tantas novelas llamadas del Oeste, así como también algunas narraciones basadas en sus experiencias por esas zonas costeras de Nueva Zelanda.

De la Isla Norte se ocupa el capítulo "La playa de las 90 millas y Cape Reinga", lugar asociado a diversas leyendas. Va después el viajero y sus acompañantes a Waimate, donde asisten a un funeral, ceremonia con un refrigerio de los asistentes una vez la fallecida es llevada al crematorio, y no sin que se desarrollase todo "con serenidad y equilibrio emocional". El día siguiente la ruta emprendida lleva al Sur, pero eligiendo "caminos secundarios para mejor contemplar la belleza que la naturaleza ofrece". Se detendrán en Roturua, la ciudad maorí más emblemática, y enclave geotermal asentado sobre el cráter de un volcán gigantesco. 
A Wellington lleva después el autor a sus lectores. Ciudad pequeña, aunque capital del país, y sede de la Universidad Victoria, a la que circunda la Salamanca Road. También una de las paradas del funicular que asciende hasta la colina lleva el nombre de Salamanca, y en ambos casos a vueltas de la participación del Duque de Wellington en las batallas de Ciudad Rodrigo y de los Arapiles durante las guerras napoleónicas.

Bien interesante resulta que Román Álvarez Rodríguez nos haya hecho caer en la cuenta de que no pocas islas de esta zona del Pacífico, entre ellas las de Cook y Fiji, en realidad son pequeños estados soberanos y, por ende, con sendos votos en la ONU que también cuentan, al margen de la exigua población de esos lugares. Al igual que en Sydney, hay en Wellington también un Paseo de los escritores. Y obviamente en la ciudad llevó a cabo el catedrático salmantino productivas gestiones en la Embajada de España y en la Universidad de Victoria.

Después de sernos referida la visita al Parque Nacional de Tongarino, el autor completa su libro con capítulos relativos a cuestiones tales como las labores campestres de esquileo; los carneros que se descarriaron, no pudiéndoseles esquilar, con el consiguiente sobrepeso encima, a veces demoledor; los vínculos entre Australia y Nueva Zelanda, así como los de ambas naciones con España, con alguna representación gastronómica en esas tierras; la participación de esos dos países en la Primera guerra mundial, y en la guerra civil española, a través de las Brigadas internacionales; y por supuesto las posibilidades de establecer un eje académico entre la Universidad de Salamanca y las de las naciones visitadas.

Requeriría aumentar esta reseña con muchas páginas más si señalásemos lo más destacado de los capítulos aludidos. Para economizar espacio señalaré tan solo unas pocas cosas leídas, como por ejemplo las siguientes: la gente joven considera que el trabajo en el campo supone una profesión de futuro; el mercado lanar de Australia y Nueva Zelanda es más cotizado que el español; perteneciendo como pertenecen ambas naciones a la Commonwelth, sus lazos habrían de estrecharse si cabe, etc.

En ocasiones sucede que los viajes congresuales y las visitas de trabajo académicas comportan, quieras que no, la posibilidad de realizar turismo, turismo cultural para conocer las zonas visitadas, y sin descender al mero turisteo fotográfico. Apenas sucede que esos viajes ocasionen libros del tipo del reseñado, de ahí que esa obra de Román Álvarez Rodríguez sea bien excepcional, además de permitirnos evidenciar las dotes muy notables de narrador de este catedrático salmantino que se ha esforzado con tanto entusiasmo en ponerse al servicio del proyecto de extender la presencia de la Universidad de Salamanca en unos horizontes tan alejados de la ribera del Tormes.

José María Balcells 